\title{
Variants of the Matrix Metalloproteinase-2 but not the Matrix Metalloproteinase-9 genes significantly influence functional outcome after stroke
}

Helena Manso ${ }^{1,2,3}$, Tiago Krug ${ }^{1,4}$, João Sobral ${ }^{1,2,3}$, Isabel Albergaria², Gisela Gaspar², José M Ferro ${ }^{5}$, Sofia A Oliveira ${ }^{1,4}$, Astrid M Vicente ${ }^{1,2,3^{*}}$

\begin{abstract}
Background: Multiple lines of evidence suggest that genetic factors contribute to stroke recovery. The matrix metalloproteinases -2 (MMP-2) and -9 (MMP-9) are modulators of extracellular matrix components, with important regulatory functions in the Central Nervous System (CNS). Shortly after stroke, MMP-2 and MMP-9 have mainly damaging effects for brain tissue. However, MMPs also have a beneficial activity in angiogenesis and neurovascular remodelling during the delayed neuroinflammatory response phase, thus possibly contributing to stroke functional recovery.
\end{abstract}

Methods: In the present study, the role of MMP-2 and MMP-9 genetic variants in stroke recovery was investigated in 546 stroke patients. Functional outcome was assessed three months after a stroke episode using the modified Rankin Scale $(\mathrm{mRS})$, and patients were classified in two groups: good recovery $(\mathrm{mRS} \leq 1)$ or poor recovery $(\mathrm{mRS}>1)$. Haplotype tagging single nucleotide polymorphisms (SNPs) in the MMP-2 $(N=21)$ and MMP-9 $(N=4)$ genes were genotyped and tested for association with stroke outcome, adjusting for significant non-genetic clinical variables.

Results: Six SNPs in the MMP-2 gene were significantly associated with stroke outcome $(0.0018<P<0.0415)$, two of which survived the Bonferroni correction for multiple testing. In the subset of ischemic stroke patients, association of five of these SNPs remained positive $(0.0042<P<0.0306)$. No significant associations were found for the MMP-9 gene.

Conclusions: The results presented strongly indicate that MMP-2 genetic variants are an important mediator of functional outcome after stroke.

\section{Background}

While remaining one of the most common causes of death worldwide, stroke is also a leading cause of significant disability: after a first stroke event, $50-70 \%$ of stroke patients regain functional independence, but 15$30 \%$ are permanently disabled and $20 \%$ require institutional care at 3 months after onset [1]. Clinical and demographic factors can influence stroke outcome. In addition, genetic factors are likely to have an impact in stroke recovery processes and outcome: family history of stroke is associated with stroke outcome [2,3] and many animal models of stroke implicate genes that regulate

\footnotetext{
* Correspondence: avicente@igc.gulbenkian.pt 'Instituto Gulbenkian de Ciência, Oeiras, Portugal
}

angiogenesis, neuronal regeneration and proliferation, and neuroinflammation, in stroke recovery [4-7].

Several lines of evidence suggest that matrix metalloproteinases (MMPs) are fundamental players in stroke recovery. These molecules belong to a family of zincdependent endopeptidases that modulate extracellular matrix (ECM) components in many Central Nervous System (CNS) developmental and regenerative processes such as neurogenesis, axonal growth and regeneration, and myelin formation. The expression and activity of MMPs is tightly regulated. Most MMPs require proteolytic processing by proteases or other MMPs to become activated, and can be inhibited by tissue inhibitors of metalloproteinases (TIMPs). Dysregulated MMP activity will lead to uncontrolled degradation of ECM and basal

C 2010 Manso et al; licensee BioMed Central Ltd. This is an Open Access article distributed under the terms of the Creative Commons 
lamina proteins, with serious harmful effects for the blood-brain barrier (BBB) integrity and neuroinflammatory or neurotoxic consequences [8,9]. Such dysregulation of MMPs is known to occur after stroke, leading to a degradation of the neurovascular matrix, disrupting cell-matrix homeostasis and weakening the BBB, and thus contributing to cell death, neurotoxicity, edema and hemorrhage $[9,10]$. The variation profiles of MMPs in blood after a stroke event $[11,12]$ suggest that these molecules can eventually be used as biomarkers for brain damage and neurological outcome, while their contribution to tissue destruction renders MMPs inhibitors potentially interesting therapeutic targets for stroke.

Emerging studies, however, indicate that MMPs may also have a beneficial activity in angiogenesis and neurovascular remodelling during the delayed neuroinflammatory response phase after stroke, possibly contributing to stroke functional recovery [9]. While inhibition of MMP activity has consistently been demonstrated to be effective in reducing edema, infarct size and hemorrhagic transformation, some studies suggest the existence of a time window for these beneficial effects to take place [13,14].

In the present study we tested the impact of genetic variants in $M M P-2$ and $M M P-9$ in stroke recovery, in a population sample of 546 patients evaluated for stroke outcome at three months after the stroke event.

\section{Methods}

Participants in the present study were recruited in the context of a wider research project to evaluate stroke risk factors in a Portuguese population sample, which enrolled first-ever stroke patients under 65 years of age through Neurology and Internal Medicine Departments of several hospitals in Portugal. Stroke was defined as a focal neurological deficit of sudden or rapid onset lasting more than 24 hours, and classified into ischemic or intracerebral hemorrhage based on brain imaging (computed tomography and/or magnetic resonance imaging). The diagnosis of stroke was confirmed by a neurologist. Demographic characteristics (age and gender), information on previous vascular risk factors and comorbid conditions (diabetes mellitus, hypertension, cardiac disease, dyslipidemia, obesity), life-style risk factors (smoking status, alcohol consumption, physical inactivity and others), and detailed clinical data during hospitalization, including neurological symptoms, complications and interventions, were collected for the majority of patients. Occurrence of aphasia, neglect, paresis, gaze paresis, dysphagia, permanent consciousness disturbance, urinary incontinence and medical and neurological complications were clinical parameters indicative of stroke severity. Stroke outcome at discharge and at three months was assessed, by direct interview, using the modified Rankin Scale (mRS).

For the present study, 568 patients with relevant clinical data and a DNA sample were available. Eight patients had a second stroke event after enrolment, affecting patient recovery, and were thus excluded. Of the remaining 560, 14 did not return after discharge for the three months evaluation, and therefore only 546 patients were included in the analysis. Patients were classified in two groups, according to their mRS at three months: patients with $\mathrm{mRS} \leq 1$ were assigned to the "good recovery" group and patients with mRS $>1$ were assigned to the "poor recovery" group (handicapped patients). 276 individuals were included in the good recovery group (63.0\% males and $37.0 \%$ females) and 270 in the poor recovery group (64.4\% males, $35.6 \%$ females). The poor recovery group included 12 patients who died before the three months evaluation (seven of them before hospital discharge, and five others after discharge). Genetic power calculations were performed using the CaTS software [15].

The study was approved by the Ethics Committee of Instituto Nacional de Saúde Dr. Ricardo Jorge and other hospitals involved, subjects gave informed consent and procedures followed were in accordance with institutional guidelines.

Single nucleotide polymorphisms (SNPs) within the $M M P-2$ and $M M P-9$ genes and up to $5 \mathrm{~kb}$ of the flanking regions were selected using the Haploview software (v4.0) [16], based on their tagging potential (HapMap Release 21/phase II July 2006). 4 SNPs in MMP-9 and 20 SNPs in $M M P-2$ were genotyped using the Sequenom iPLEX assays with allele detection by mass spectroscopy, using Sequenom MassARRAY technology (Sequenom, San Diego, USA) and following the manufacturer's protocol. Primer sequences were designed using Sequenom's MassARRAY Assay Design 3.0 software. 1 SNP in MMP-2 was genotyped using TaqMan ${ }^{\circ}$ Pre-Designed SNP Genotyping Assays, in an ABI PRISM 7900HT Sequence Detector System (Applied Biosystems, Foster City, USA). Extensive quality control was performed using eight HapMap individuals, duplicated samples within and across genotyping plates, Mendelian segregation in three pedigrees and no-template samples. Call rates $<90 \%$ and deviation from Hardy-Weinberg equilibrium led to SNP exclusion from the analysis. 2 SNPs in MMP-9 failed quality control and were substituted. In total, $21 M M P-2$ SNPs and 4 $M M P-9$ SNPs were analysed.

The effect of discrete and continuous non-genetic variables on stroke outcome at three months was determined using the Pearson $\chi^{2}$ test and Mann-Whitney 
test, respectively. These included age, gender, stroke risk factors as well as data on clinical variables collected during hospitalization (like occurrence of paresis, aphasia and medical complications). Variables with a $P<0.25$ in univariate analysis or of particular clinical relevance were included in a logistic regression model using forward selection [17] and were maintained in the model if they were associated at a $P \leq 0.05$ level with stroke outcome. Logistic regression analyses were then used to determine the effect of each genetic variable on stroke outcome after adjustment for those significant nongenetic variables. Odds ratio (OR) and 95\% confidence intervals $(95 \% \mathrm{CI})$ were computed for the log-additive model. Univariate and logistic regression analyses were performed using MASS and SNPassoc packages of the R software [18] (v2.6.0). The Gabriel et al. (2002) [19] default method of the Haploview software [16] (v4.0) was used to determine haplotype blocks in the $M M P-2$ and $M M P-9$ genes. Since recovery processes may be regulated differently in ischemic and hemorrhagic stroke patients, we performed the same analyses in the subset of ischemic stroke patients. The small number of hemorrhagic stroke patients $(\mathrm{N}=105)$ precluded the independent analysis of this subset.

Significant associations in individual SNP analysis were corrected for multiple testing using the Bonferroni method. The alternative SNPSpD approach, based on the spectral decomposition ( $\mathrm{SpD}$ ) of matrices of pairwise linkage disequilibrium (LD) between SNPs was also applied [20]. Since some of the 21 SNPs genotyped in the $M M P-2$ gene are in LD with each other in our sample, we used the SNPSpD approach to estimate the effective number of independent SNPs in our sample for multiple testing corrections.

\section{Results}

Clinical and demographic characteristics of the population sample are presented in Table 1 . Univariate analysis showed that type of stroke and six clinical features indicative of stroke severity - occurrence of aphasia, urinary incontinence, paresis, consciousness disturbance, medical and neurological complications during hospitalization - were significant predictors of poor outcome. Sex ratio, age, and stroke risk factors were similar between the poor and good recovery groups, and approximately the same proportion of patients was being treated for hypertension in either group $(34.0 \%$ and $34.6 \%$ in the good and poor recovery groups, respectively). Assuming an additive genetic model and disease allele frequency of $30 \%$, our sample was $82 \%$ powered to detect a genotype relative risk of 1.5 with a type I error of $5 \%$.
Of 21 MMP-2 SNPs, six were associated with stroke outcome at three months under a log-additive model $(0.0018<P<0.0415)$ after adjusting for the significant covariates in a multivariate model: history of hypertension, type of stroke, occurrence of aphasia, paresis, consciousness disturbance and medical complications during hospitalization (Table 2; see Additional file 1). History of hypertension, although not associated in the univariate analysis, became significant in the multivariate model before inclusion of genetic variants, and was therefore included in the final regression model. SNPs rs2241145 and rs1992116 remained significantly associated with stroke outcome after Bonferroni correction for multiple testing $(\mathrm{OR}[95 \% \mathrm{CI}]=1.66$ [1.20-2.30], corrected $P=0.0439$, and OR $[95 \% \mathrm{CI}]=1.67[1.20-2.31]$, corrected $P=0.0385$, respectively). Two haplotypes (one of which rare) were nominally associated with stroke outcome at three months (Table 3, Figure 1A; see Additional file 2).

The hypothesis that the recovery processes after ischemic and hemorrhagic stroke may be different and regulated by different sets of genes $[21,22]$ led us to analyze the ischemic stroke subset independently. The haemorrhagic subset was too small for independent analysis $(\mathrm{N}=105)$. In the ischemic stroke sample, five out of the previously associated SNPs in the $M M P-2$ gene remained significantly associated with stroke outcome at three months under a log-additive model $(0.0042<P<$ $0.0306)$, after adjusting for the same significant covariates (excluding type of stroke) (Table 2; see Additional file 1). ORs for these SNPs in this subset were similar to the overall study sample. None of the SNPs remained significant after Bonferroni correction for multiple testing. However, when the SNPSpD method was used, taking into account regional LD patterns and therefore the number of SNPs which are effectively independent, the two SNPs that survived Bonferroni correction in the whole sample remained significant for the ischemic stroke subset (rs2241145 and rs1992116) (see Additional file 1). Four additional $M M P-2$ SNPs were nominally associated with ischemic stroke outcome at three months $(0.0162<P<0.0412$, Table 2$)$. Only one haplotype in $M M P-2$ was also associated (Table 3; see Additional file 2).

OR analysis indicates that, for the majority of significantly associated SNPs (including rs2241145 and rs1992116), carriers of the minor allele (less frequent allele) are significant predictors of poor outcome $(\mathrm{OR}>1)$; only for rs 243842 in the whole population sample, and for rs857403 and rs183112 in the ischemic subset, carriers of the minor allele show an improved chance of good recovery from stroke $(\mathrm{OR}<1)$. 
Table 1 Demographic and clinical characteristics of stroke patients

\begin{tabular}{|c|c|c|c|}
\hline Characteristic & Good Recovery (mRS $\leq 1)$ & Poor Recovery (mRS>1) & $P^{*}$ \\
\hline \multicolumn{4}{|l|}{ Age and Gender } \\
\hline Age, mean \pm SD (yrs) & $50.8 \pm 9$ & $52.5 \pm 8.5$ & 0.028 \\
\hline Gender (male), n/N (\%) & $174 / 276(63.0)$ & $174 / 270(64.4)$ & 0.734 \\
\hline \multicolumn{4}{|l|}{ Past History, n/N (\%) } \\
\hline Hypertension & $159 / 241(66.0)$ & $143 / 240(59.6)$ & 0.147 \\
\hline Diabetes & $36 / 259(13.9)$ & 47/246 (19.1) & 0.115 \\
\hline Cardiac Disease & $37 / 264(14.0)$ & $43 / 257(16.7)$ & 0.390 \\
\hline \multicolumn{4}{|l|}{ Sroke type, n/N (\%) } \\
\hline Ischemic stroke & 238/276 (86.2) & $193 / 270(71.5)$ & - \\
\hline Hemorrhagic stroke & $33 / 276(12.0)$ & $72 / 270(26.7)$ & - \\
\hline Unknow type of stroke & 5/276 (1.8) & $5 / 270(1.9)$ & - \\
\hline \multicolumn{4}{|l|}{ Stroke Features, n/N (\%) } \\
\hline Aphasia & $53 / 258(20.5)$ & $98 / 250(39.2)$ & $4.23 \times 10^{-6}$ \\
\hline Neglect & $11 / 266(4.1)$ & 19/240 (7.9) & 0.072 \\
\hline Dysphagia & $15 / 270(5.6)$ & $25 / 251(10.0)$ & 0.059 \\
\hline Urinary Incontinence & $5 / 272(1.8)$ & 15/251 (6.0) & 0.014 \\
\hline Paresis & 203/273 (74.4) & $244 / 269(90.7)$ & $5.59 \times 10^{-7}$ \\
\hline Consciousness disturbance & $21 / 275(7.6)$ & $59 / 265(22.3)$ & $1.72 \times 10^{-6}$ \\
\hline Medical complications & 18/265 (6.8) & $82 / 254(32.3)$ & $1.83 \times 10^{-13}$ \\
\hline Neurologic complications & $14 / 274(5.1)$ & $39 / 267(14.6)$ & $2.03 \times 10^{-4}$ \\
\hline
\end{tabular}

*Mann-Whitney test or $\chi^{2}$ test.

SD - standard deviation, yrs - years.

In the MMP-9 gene, one rare haplotype was associated with stroke outcome in the overall population sample $(P=0.0065$, Table 3, Figure 1B; see Additional file 2), but no independent association was found for any of the four tested SNPs (see Additional file 1). No SNP or haplotype in the $M M P-9$ gene was associated with stroke outcome at three months in the ischemic subset (see Additional files 1 and 2).

None of the tested SNPs were associated with hypertension, indicating that the MMP-2 effect on recovery was not mediated by its role on vascular structure (data not shown).

Two of the MMP-2 SNPs (rs1053605 and rs243849) are located in exonic regions of the $M M P-2$ gene (exons 5 and 7, respectively), two SNPs (rs243866 and rs243865) are located upstream of the gene, and six SNPs are intronic (Figure 1A). Both nucleotide transitions in the exonic SNPs are silent. To investigate possible functional consequences for gene transcription of the two upstream SNPs (rs243866 and rs243865) and the two intronic SNPs that survived correction for multiple testing (rs2241145 and rs1992116), we conducted a bioinformatics search for putative transcription factor binding sites. The A allele of the upstream SNP rs243866 lies in the core of a sequence with high similarity to the matrix for two binding factors, the IPF1 (insulin promoter factor 1), and the POU5F1 (POU domain class 5 transcription factor 1). Both proteins are transcription activators. Since the AA and AG genotypes are more frequent in the poor recovery group, we can hypothesize that the presence of the A allele may lead to an increased transcription of the $M M P-2$ gene, and thus explain the negative impact on stroke recovery observed in this population sample. The presence of the $\mathrm{T}$ allele in the upstream rs 243865 SNP forms a sequence with high similarity to the matrix for the PLZF binding factor (promyelocytic leukemia zinc finger protein), while the sequence containing the $C$ allele has a stronger similarity with the matrix for the VDR/RXR (vitamin D hormone receptor/retinoid $\times$ receptor) heterodimer. However, both transcription factors act as repressors, and therefore these findings are more difficult to interpret. The rs2241145 and rs1992116 intronic SNPs did not contain sequences for any known putative transcription factor binding sites.

\section{Discussion}

In the present study we show that $M M P$-2 gene variants are strongly associated with patient's functional 
Table 2 Genotype frequency distribution and association with stroke outcome at three months for MMP-2 SNPs

\begin{tabular}{|c|c|c|c|c|c|c|c|c|c|}
\hline \multirow[b]{3}{*}{ SNP } & \multirow[b]{3}{*}{ Genotype } & \multicolumn{4}{|c|}{ Whole sample* } & \multicolumn{4}{|c|}{ Ischemic subset $^{\dagger}$} \\
\hline & & \multicolumn{2}{|c|}{ Genotype frequency } & \multirow[b]{2}{*}{ OR $[95 \% \mathrm{Cl}]$} & \multirow[b]{2}{*}{$P$} & \multicolumn{2}{|c|}{ Genotype frequency } & \multirow[b]{2}{*}{ OR $[95 \% \mathrm{Cl}]$} & \multirow[b]{2}{*}{$P$} \\
\hline & & $\begin{array}{c}\text { Good recovery, } \\
\text { n (\%) }\end{array}$ & $\begin{array}{c}\text { Poor recovery, } \\
\text { n (\%) }\end{array}$ & & & $\begin{array}{c}\text { Good recovery, } \\
\text { n (\%) }\end{array}$ & $\begin{array}{c}\text { Poor recovery, } \\
\text { n (\%) }\end{array}$ & & \\
\hline \multicolumn{10}{|c|}{ rs243866 } \\
\hline & $\mathrm{G} / \mathrm{G}$ & $142(67.6)$ & $117(57.9)$ & $1.67[1.10-2.52]$ & 0.0143 & 125 (67.6) & $83(56.8)$ & 1.78 [1.13-2.80] & 0.0128 \\
\hline & $\mathrm{A} / \mathrm{G}$ & 66 (31.4) & $76(37.6)$ & & & 59 (31.9) & $55(37.7)$ & & \\
\hline & A/A & $2(1.0)$ & $9(4.5)$ & & & $1(0.5)$ & $8(5.5)$ & & \\
\hline \multicolumn{10}{|c|}{ rs243865 } \\
\hline & $\mathrm{C} / \mathrm{C}$ & $141(67.8)$ & $117(57.9)$ & 1.65 [1.09-2.50] & 0.0162 & $124(67.8)$ & $83(56.8)$ & $1.76[1.12-2.78]$ & 0.0143 \\
\hline & $\mathrm{C} / \mathrm{T}$ & $65(31.2)$ & 76 (37.6) & & & $58(31.7)$ & $55(37.7)$ & & \\
\hline & $\mathrm{T} / \mathrm{T}$ & $2(1.0)$ & $9(4.5)$ & & & $1(0.5)$ & $8(5.5)$ & & \\
\hline
\end{tabular}

rs857403

\begin{tabular}{|c|c|c|c|c|c|c|c|}
\hline A/A & $124(59.3)$ & $138(68.3)$ & $0.71[0.48-1.06]$ & 0.0909 & 105 (57.1) & 103 (70.5) & 0.62 [0.40-0.97] \\
\hline T/A & 75 (35.9) & $56(27.7)$ & & & $70(38)$ & $37(25.3)$ & \\
\hline T/T & $10(4.8)$ & $8(4.0)$ & & & $9(4.9)$ & $6(4.1)$ & \\
\hline
\end{tabular}

rs1477017

\begin{tabular}{|c|c|c|c|c|c|c|c|}
\hline $\mathrm{A} / \mathrm{A}$ & $100(47.6)$ & $81(40.1)$ & 1.42 [1.01-2.00] & 0.0415 & $86(46.5)$ & $55(37.7)$ & $1.51[1.04-2.20]$ \\
\hline $\mathrm{G} / \mathrm{A}$ & $91(43.3)$ & $98(48.5)$ & & & $82(44.3)$ & $72(49.3)$ & \\
\hline $\mathrm{G} / \mathrm{G}$ & $19(9.0)$ & $23(11.4)$ & & & $17(9.2)$ & $19(13)$ & \\
\hline
\end{tabular}

rs17301608

\begin{tabular}{|c|c|c|c|c|c|c|c|}
\hline $\mathrm{C} / \mathrm{C}$ & $94(45.0)$ & 75 (37.3) & 1.40 [1.00-1.95] & 0.0510 & $80(43.5)$ & $50(34.5)$ & $1.47[1.01-2.12]$ \\
\hline $\mathrm{C} / \mathrm{T}$ & $94(45.0)$ & $100(49.8)$ & & & $85(46.2)$ & $73(50.3)$ & \\
\hline$T / T$ & $21(10.0)$ & 26 (12.9) & & & 19 (10.3) & $22(15.2)$ & \\
\hline
\end{tabular}

rs1053605

\begin{tabular}{|c|c|c|c|c|c|c|c|}
\hline $\mathrm{C} / \mathrm{C}$ & 188 (89.5) & $170(84.2)$ & $2.02[1.09-3.75]$ & 0.0227 & 166 (89.7) & $127(87.0)$ & $1.82[0.93-3.58]$ \\
\hline$C / T$ & $22(10.5)$ & $28(13.9)$ & & & $19(10.3)$ & $16(11.0)$ & \\
\hline$T / T$ & $0(0.0)$ & $4(2.0)$ & & & $0(0.0)$ & $3(2.0)$ & \\
\hline
\end{tabular}

rs 2241145

\begin{tabular}{|c|c|c|c|c|c|c|c|}
\hline $\mathrm{G} / \mathrm{G}$ & 79 (37.8) & $56(27.9)$ & 1.66 [1.20-2.30] & $0.0021^{\neq}$ & $68(37.0)$ & 39 (26.9) & $1.67[1.17-2.40]$ \\
\hline $\mathrm{G} / \mathrm{C}$ & $100(47.8)$ & $101(50.2)$ & & & $88(47.8)$ & 72 (49.7) & \\
\hline $\mathrm{C} / \mathrm{C}$ & $30(14.4)$ & 44 (21.9) & & & $28(15.2)$ & $34(23.4)$ & \\
\hline
\end{tabular}

rs243849

\begin{tabular}{|c|c|c|c|c|c|c|c|c|}
\hline $\mathrm{C} / \mathrm{C}$ & $131(62.7)$ & $143(71.5)$ & 0.70 [0.46-1.07] & 0.0948 & $112(60.9)$ & $108(75)$ & 0.59 [0.36-0.96] & 0.0314 \\
\hline $\mathrm{T} / \mathrm{C}$ & 70 (33.5) & $52(26.0)$ & & & 65 (35.3) & $33(22.9)$ & & \\
\hline $\mathrm{T} / \mathrm{T}$ & $8(3.8)$ & $5(2.5)$ & & & $7(3.8)$ & $3(2.1)$ & & \\
\hline
\end{tabular}

rs183112

\begin{tabular}{|c|c|c|c|c|c|c|c|}
\hline $\mathrm{G} / \mathrm{G}$ & $134(64.1)$ & $145(72.9)$ & 0.66 [0.43-1.03] & 0.0669 & $115(62.5)$ & $110(76.9)$ & $0.54[0.32-0.90]$ \\
\hline $\mathrm{A} / \mathrm{G}$ & $70(33.5)$ & $51(25.6)$ & & & 65 (35.3) & $32(22.4)$ & \\
\hline $\mathrm{A} / \mathrm{A}$ & $5(2.4)$ & $3(1.5)$ & & & $4(2.2)$ & $1(0.7)$ & \\
\hline
\end{tabular}


Table 2: Genotype frequency distribution and association with stroke outcome at three months for MMP-2 SNPs (Continued)

\begin{tabular}{|c|c|c|c|c|c|c|c|c|c|}
\hline \multicolumn{10}{|l|}{ rs1992116 } \\
\hline & $\mathrm{G} / \mathrm{G}$ & $87(41.6)$ & 65 (32.3) & $1.67[1.20-2.31]$ & $0.0018^{\ddagger}$ & 76 (41.3) & $48(33.1)$ & $1.68[1.17-2.42]$ & 0.0042 \\
\hline & $A / G$ & $97(46.4)$ & $94(46.8)$ & & & $86(46.7)$ & $67(46.2)$ & & \\
\hline & A/A & $25(12.0)$ & $42(20.9)$ & & & $22(12.0)$ & $30(20.7)$ & & \\
\hline
\end{tabular}

95\% Cl - 95\% Confidence Interval.

${ }^{*} \mathrm{OR}[95 \% \mathrm{Cl}]$ and $P$ for the log-additive genetic model after adjustment for significant covariates (history of hypertension, type of stroke, and occurrence of aphasia, paresis, consciousness disturbance and complications during hospitalization).

${ }^{+} \mathrm{OR}[95 \% \mathrm{Cl}]$ and $P$ for the log-additive genetic model after adjustment for significant covariates (history of hypertension, and occurrence of aphasia, paresis, consciousness disturbance and complications during hospitalization).

FSignificant result after Bonferroni correction.

Results were adjusted for significant covariates; Odds Ratio $(\mathrm{OR})>1$ indicates increased probability of poor recovery for the carriers of the minor allele; only associated SNPs are shown.

disability at three months after stroke onset, in a large Portuguese population sample. Given the possible genetic heterogeneity in recovery processes after hemorrhagic and ischemic stroke [21,22], we also analysed the association of this gene with stroke outcome in the restricted subgroup of ischemic stroke patients. All but one $M M P-2$ gene variants associated with stroke in the overall population sample remained associated with ischemic stroke in this smaller subset. Additional markers were associated only in this subset, possibly reflecting the increased genetic homogeneity of the ischemic group in terms of recovery processes. Associated SNPs in the ischemic subset did not, however, withstand Bonferroni correction for multiple testing. This could reflect the reduction in power due to the smaller sample size in the restricted analysis and/ or the overcorrection for the false positive rate that is the main frequent criticism for this method. In fact, the alternative SNPSpD approach [20], which takes into account LD patterns between genotyped SNPs in the tested population, may be more appropriate since the 21 genotyped $M M P-2$ SNPs are not independent; with this approach, the significance of association of two specific SNPs with stroke, in the ischemic subset or in the overall population sample, was retained after multiple testing correction. The association results after multiple testing correction, using the stringent Bonferroni method or the SNPSpD approach, strongly support a role for $M M P-2$ in stroke recovery. Validation through replication in a larger sample set by other groups is now advisable.

A limitation of the present study was the lack of availability of the National Institute of Health Stroke Scale (NIHSS) for these patients. To control for the effect of the severity of stroke in patients' outcome, we performed a logistic regression analysis using, as covariates, individual clinical variables associated with stroke clinical severity in our sample. Each selected variable was entered in the logistic regression model to identify those behaving as clinical predictors of stroke outcome. While this approach may not be as comprehensive as a widely used severity scale, it allowed us to include in the analysis parameters that reflect the severity of the event and, to a certain extent, patient's status at baseline.

While subject of controversy, the cut-off for the good and poor recovery groups was set between 1 and 2 because we chose to focus on a non-handicaped recovery group. According to Weisscher et al. (2008) [23], there is a clear lag on performance of outdoor activities between mRS 1 and 2, while between mRS 2 and 3 the major difference is the ability to perform complex activities of daily life, and thus a more clearly defined good outcome is given by setting the cut-off between mRS 1 and 2 .

Multiple studies in animal models and humans have shown that the actions of MMPs contribute to BBB disruption and brain cell death, early after a stroke event. These damaging processes can be inhibited by MMP inhibitors, leading to reductions in infarct volume and significant improvements in behavioural scores compared with controls [10]. However, fitting with their role in development and regeneration, a beneficial influence of MMPs in the recovery processes that occur in later stages after a stroke event, including angiogenesis, remyelination, neural migration and general recovery of the neurovascular unit has been shown $[13,14,24,25]$. At present, we cannot dissect whether gene variation in $M M P-2$ is more important for the damaging effects in the earlier stages after stroke, or to the beneficial delayed responses, or both. Functional studies will be required to answer this question. However, the present findings may have important implications. On one hand it challenges the usefulness of MMP inhibitors for the treatment of stroke, not only because the time window of usefulness is likely limited, but also because it may depend on the individual's $M M P-2$ genotype. On the other hand, and given 
Table 3 Haplotype frequency distribution of the MMP-2 and -9 genes, and association with stroke outcome

\begin{tabular}{|c|c|c|c|c|c|c|c|c|c|c|c|}
\hline \multirow[b]{2}{*}{ Gene } & \multirow[b]{2}{*}{ Haplotype } & \multicolumn{5}{|c|}{ Whole sample } & \multicolumn{5}{|c|}{ Ischemic subset } \\
\hline & & $\begin{array}{l}\text { Haplotype } \\
\text { frequency }\end{array}$ & $\begin{array}{l}\text { Good } \\
\text { recovery } \\
(\%)\end{array}$ & $\begin{array}{l}\text { Poor } \\
\text { recovery } \\
(\%)\end{array}$ & $\chi^{2}$ & $P$ & $\begin{array}{l}\text { Haplotype } \\
\text { frequency }\end{array}$ & $\begin{array}{l}\text { Good } \\
\text { recovery } \\
(\%)\end{array}$ & $\begin{array}{l}\text { Poor } \\
\text { recovery } \\
(\%)\end{array}$ & $\chi^{2}$ & $P$ \\
\hline \multirow[t]{2}{*}{ MMP-2 } & rs11643630-rs243866-rs243865 & 0.200 & 17.2 & 22.7 & 5.150 & 0.0233 & 0.198 & 16.8 & 23.5 & 6.125 & 0.0133 \\
\hline & TAT & & & & & & & & & & \\
\hline \multirow[t]{2}{*}{$M M P-2$} & $\begin{array}{c}\text { rs1477017-rs17301608- } \\
\text { rs1132896-rs1053605- } \\
\text { rs2241145-rs243849-rs243842- } \\
\text { rs183112 }\end{array}$ & 0.011 & 1.8 & 0.4 & 4.776 & 0.0289 & 0.014 & 2.1 & 0.6 & 3.372 & 0.0663 \\
\hline & ACGCGTTG & & & & & & & & & & \\
\hline \multirow[t]{2}{*}{ MMP-9 } & $\begin{array}{c}\text { rs8113877-rs3918253- } \\
\text { rs2236416 }\end{array}$ & 0.034 & 4.8 & 1.9 & 7.403 & 0.0065 & 0.038 & 4.9 & 2.4 & 3.680 & 0.0551 \\
\hline & TCA & & & & & & & & & & \\
\hline
\end{tabular}

Only haplotypes with significant association results are presented.

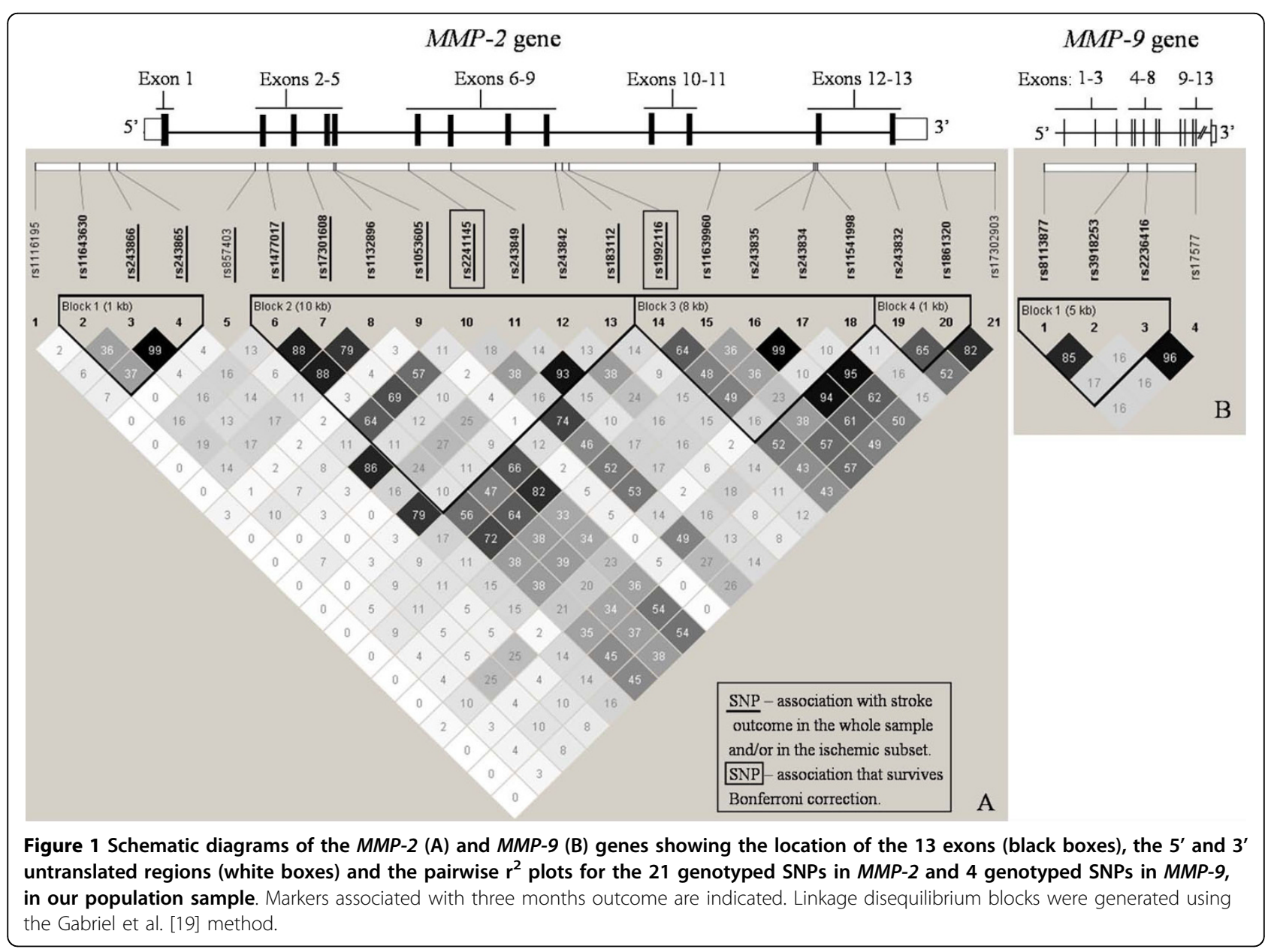

that MMP-2 has also been suggested to influence the risk of hemorrhagic transformation upon recombinant tissue plasminogen activator (tPA) therapy [26], it is a plausible hypothesis that treatment outcome may also be associated with $M M P-2$ gene variants. Further work needs to be carried out to elucidate these questions.

\section{Conclusions}

The present study further reinforces the contribution of MMPs for stroke recovery by showing that specific $M M P-2$, but not $M M P-9$, gene variants influence stroke outcome. Replication of these associations in larger population samples, together with approaches that 
integrate evidence from multiple levels, including gene expression and functional analysis, will contribute for the validation of these results. Together with previous observations, the study leads to the hypothesis that individual variation in the $M M P-2$ gene may influence stroke treatment outcome.

Additional file 1: Table 4: Association analysis results for MMP-2 and MMP-9 SNPs and stroke outcome. Association analysis results for MMP-2 and MMP-9 SNPS and stroke outcome.

Additional file 2: Table 5: Association analysis results for MMP-2 and MMP-9 haplotypes and stroke outcome. Association analysis results for MMP-2 and MMP-9 haplotypes and stroke outcome.

\section{Acknowledgements}

The authors are grateful to all study participants and their families. The study subjects in this study were recruited in the context of an earlier study designated "Acidentes Vasculares Cerebrais antes dos 65 anos", funded by Fundação para a Ciência e a Tecnologia (FCT) (PECS/T/SAU/179/95). The authors wish to thank Dr. Marinho Falcão and his team at Instituto Nacional de Saúde Dr. Ricardo Jorge, and all the clinicians that recruited study subjects from the following hospitals: H. S. João, H. Évora, H. Funchal, H. Marmeleiros, H. S. Bento, H. S. José, H. S. Marcos, H. Garcia d'Orta, H. Faro, H. Coimbra, H. Vila Nova de Gaia, H. Aveiro, SAMS, H. Capuchos and H. Sto. António. The authors also wish to thank the technical assistance provided by the Genotyping Unit at Instituto Gulbenkian de Ciência. This work was supported in part by the Marie Curie International Reintegration Grant 513760 (SAO), the Marie Curie Intra-European Fellowship 024563 (SAO), the FCT grant PTDC/SAU-GMG/64426/2006, and fellowships from FCT (HM, TK) and the Portuguese Instituto do Emprego e Formação Profissional (TK).

\section{Author details}

'Instituto Gulbenkian de Ciência, Oeiras, Portugal. ${ }^{2}$ Departamento Promoção da Saúde e Doenças Crónicas, Instituto Nacional de Saúde Dr Ricardo Jorge, Lisbon, Portugal. ${ }^{3}$ Center for Biodiversity, Functional \& Integrative Genomics (BIOFIG), Lisbon, Portugal. ${ }^{4}$ Clinical Neurology Research Unit, Instituto de Medicina Molecular, Faculdade de Medicina da Universidade de Lisboa, Lisbon, Portugal. ${ }^{5}$ Serviço de Neurologia, Hospital de Santa Maria, Lisbon, Portugal.

\section{Authors' contributions}

HM participated in the study design, carried out genotyping, performed the analysis and wrote the manuscript. TK carried out genotyping. JS carried out genotyping and performed the analysis. IA participated in the study design and sample collection. GG participated in the sample collection and databasing. JMF participated in the patient recruitment and evaluation, in the study design and revised the manuscript. SAO participated in the study design and revised the manuscript. AMV designed the study, performed the analysis, and wrote the manuscript. All authors read and approved the final manuscript.

\section{Competing interests}

The authors declare that they have no competing interests.

Received: 1 October 2009 Accepted: 11 March 2010 Published: 11 March 2010

\section{References}

1. Asplund K, Stegmayr B, Peltonen M: From the twentieth to the twentyfirst century: a public health perspective on stroke. Cerebrovascular Disease Pathophysiology, Diagnosis, and Management Oxford, UK: Blackwell ScienceGinsberg MD, Bogousslavsky J 1998, 2:901-918.
2. Jood K, Ladenvall C, Rosengren A, Blomstrand C, Jern C: Family History in Ischemic Stroke Before 70 Years of Age. The Sahlgrenska Academy Study on Ischemic Stroke. Stroke 2005, 36:1383-1387.

3. Lisabeth LD, Smith MA, Brown DL, Uchino K, Morgenstern LB: Family history and stroke outcome in a bi-ethnic, population-based stroke surveillance study. BMC Neurol 2005, 5:20.

4. McColl BW, McGregor AL, Wong A, Harris JD, Amalfitano A, Magnoni S, Baker AH, Dickson G, Horsburgh K: APOE epsilon3 gene transfer attenuates brain damage after experimental stroke. J Cereb Blood Flow Metab 2007, 27(3):477-487.

5. Nygren J, Kokaia $\mathrm{M}$, Wieloch $\mathrm{T}$ : Decreased expression of brain-derived neurotrophic factor in $\mathrm{BDNF}(+/-)$ mice is associated with enhanced recovery of motor performance and increased neuroblast number following experimental stroke. J Neurosci Res 2006, 84(3):626-631.

6. Sun Y, Jin K, Xie L, Childs J, Mao XO, Logvinova A, Greenberg DA: VEGFinduced neuroprotection, neurogenesis, and angiogenesis after focal cerebral ischemia. J Clin Invest 2003, 111(12):1843-1851.

7. Svedin P, Hagberg H, Savman K, Zhu C, Mallard C: Matrix metalloproteinase-9 gene knock-out protects the immature brain after cerebral hypoxia-ischemia. J Neurosci 2007, 27(7):1511-1518.

8. Candelario-Jalil E, Yang Y, Rosenberg GA: Diverse roles of matrix metalloproteinases and tissue inhibitors of metalloproteinases in neuroinflammation and cerebral ischemia. Neuroscience 2009, 158(3):983-994.

9. Rosell A, Lo EH: Multiphasic roles for matrix metalloproteinases after stroke. Curr Opin Pharmacol 2008, 8(1):82-89.

10. Gu Z, Cui J, Brown S, Fridman R, Mobashery S, Strongin AY, Lipton SA: A highly specific inhibitor of matrix metalloproteinase-9 rescues laminin from proteolysis and neurons from apoptosis in transient focal cerebral ischemia. J Neurosci 2005, 25(27):6401-6408.

11. Horstmann S, Kalb P, Koziol J, Gardner H, Wagner S: Profiles of matrix metalloproteinases, their inhibitors, and laminin in stroke patients: influence of different therapies. Stroke 2003, 34(9):2165-2170.

12. Horstmann S, Su Y, Koziol J, Meyding-Lamade U, Nagel S, Wagner S: MMP-2 and MMP-9 levels in peripheral blood after subarachnoid hemorrhage. J Neurol Sci 2006, 251(1-2):82-86.

13. Sood RR, Taheri S, Candelario-Jalil E, Estrada EY, Rosenberg GA: Early beneficial effect of matrix metalloproteinase inhibition on blood-brain barrier permeability as measured by magnetic resonance imaging countered by impaired long-term recovery after stroke in rat brain. $J$ Cereb Blood Flow Metab 2008, 28(2):431-438.

14. Zhao BQ, Wang S, Kim HY, Storrie H, Rosen BR, Mooney DJ, Wang X, Lo EH: Role of matrix metalloproteinases in delayed cortical responses after stroke. Nat Med 2006, 12(4):441-445.

15. Skol AD, Scott LJ, Abecasis GR, Boehnke M: Joint analysis is more efficient than replication-based analysis for two-stage genome-wide association studies. Nature Genetics 2006, 38:209-213.

16. Barrett JC, Fry B, Maller J, Daly MJ: Haploview: analysis and visualization of LD and haplotype maps. Bioinformatics 2005, 21(2):263-265.

17. Hosmer DW, Lemeshow S: Applied Logistic Regression New York: John Wiley \& Sons, Inc, 22000.

18. R Development Core Team: R: A language and Environment for Statistical Computing. Vienna 2004 [http://www.r-project.org].

19. Gabriel SB, Schaffner SF, Nguyen H, Moore JM, Roy J, Blumenstiel B, Higgins J, DeFelice M, Lochner A, Faggart M, et al: The structure of haplotype blocks in the human genome. Science 2002, 296(5576):2225-2229.

20. Nyholt DR: A simple correction for multiple testing for single-nucleotide polymorphisms in linkage disequilibrium with each other. Am J Hum Genet 2004, 74:765-769.

21. Mehta SL, Manhas N, Raghubir R: Molecular targets in cerebral ischemia for developing novel therapeutics. Brain Res Rev 2007, 54(1):34-66.

22. Xi G, Keep RF, Hoff JT: Mechanisms of brain injury after intracerebral haemorrhage. Lancet Neurol 2006, 5:53-63.

23. Weisscher N, Vermeulen M, Roos YB, De Haan RJ: What should be defined as good outcome in stroke trials; a modified Rankin score of 0-1 or 0-2? J Neurol 2008, 255:867-874 
24. Girolamo F, Virgintino D, Errede M, Capobianco C, Bernardini N, Bertossi M, Roncali L: Involvement of metalloprotease-2 in the development of human brain microvessels. Histochem Cell Biol 2004, 122(3):261-270.

25. Hsu JY, McKeon R, Goussev S, Werb Z, Lee JU, Trivedi A, NobleHaeusslein L: Matrix metalloproteinase-2 facilitates wound healing events that promote functional recovery after spinal cord injury. J Neurosci 2006, 26(39):9841-9850.

26. Liu XS, Zhang ZG, Zhang L, Morris DC, Kapke A, Lu M, Chopp M: Atorvastatin downregulates tissue plasminogen activator-aggravated genes mediating coagulation and vascular permeability in single cerebral endothelial cells captured by laser microdissection. $J$ Cereb Blood Flow Metab 2006, 26(6):787-796.

\section{Pre-publication history}

The pre-publication history for this paper can be accessed here: http://www. biomedcentral.com/1471-2350/11/40/prepub

doi:10.1186/1471-2350-11-40

Cite this article as: Manso et al: Variants of the Matrix

Metalloproteinase-2 but not the Matrix Metalloproteinase-9 genes

significantly influence functional outcome after stroke. BMC Medical

Genetics 2010 11:40.

\section{Submit your next manuscript to BioMed Central} and take full advantage of:

- Convenient online submission

- Thorough peer review

- No space constraints or color figure charges

- Immediate publication on acceptance

- Inclusion in PubMed, CAS, Scopus and Google Scholar

- Research which is freely available for redistribution

Submit your manuscript at www.biomedcentral.com/submit 